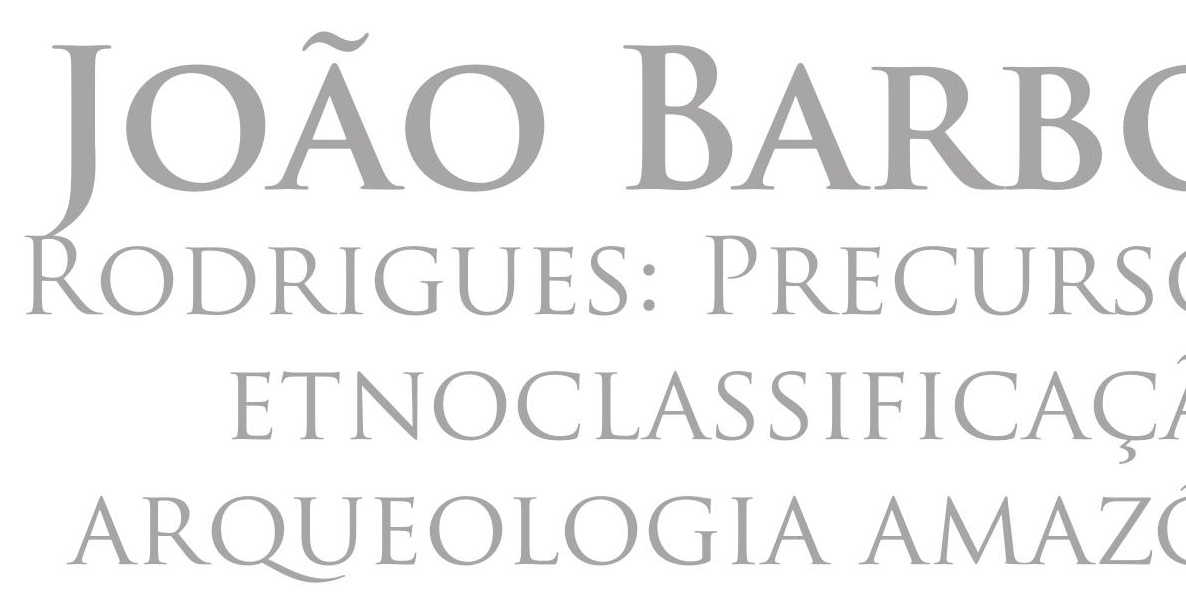




\section{JOÃO BARBOSA RODRIGUES: PRECURSOR DA ETNOCLASSIFICAÇÃO NA ARQUEOLOGIA AMAZÔNICA}

\section{L Ú C I O M E N E Z E S F E R R E I RA}

Universidade Federal de Pelotas, Brasil

\section{F R A N C I S C O S I L V A N O E L L I}




\section{Resumo}

A classificação é uma das principais tarefas da Ciência, servindo aos mais variados objetivos. Para a Arqueologia é uma das ferramentas centrais para a compreensão do conteúdo, da forma, dos significados, da distribuição espacial e da cronologia da cultura material. No continente americano, o paradigma classificatório predominou até a década de 1940. No Brasil, podemos dizer que predominou até o final da década de 1980. A história da arqueologia brasileira revela que foram adotadas diversas estratégias de classificação, quase todas relacionadas com escolas européias e americanas que principiaram na segunda metade do século XIX. Contudo, as razões que levaram os pesquisadores a decidirem por uma determinada maneira de classificar no Brasil ainda são pouco conhecidas. Nosso objetivo é apresentar a classificação estabelecida por João Barbosa Rodrigues, um dos primeiros a estabelecer um método para ordenar os registros arqueológicos no Brasil. De 1875 até 1899, ele assumiu uma posição singular e original na arqueologia brasileira, fortemente influenciada pela sistemática e pelas teorias lingüísticas de Karl P. von Martius.

Palavras-chave: João Barbosa Rodrigues; História da Arqueologia Brasileira; Etnoclassificação.

\section{Resumen}

La clasificación es una tarea clave para la Ciencia, al servicio de los más diversos objetivos. Para la arqueología es una de las herramientas centrales para comprender el contenido, la forma de significados, la distribución espacial y la cronología de la cultura material. En las Américas, el paradigma de clasificación predominó hasta la década de 1940. En Brasil, podemos decir que prevaleció hasta finales del decenio de 1980. La historia de la arqueología brasileña enseña que se adoptaron diferentes estrategias para la clasificación, casi todas relacionadas con las escuelas europeas y americanas establecidas en la segunda mitad del siglo XIX. Sin embargo, las razones que han llevado a los investigadores a decidir por una manera determinada de clasificar en Brasil son todavía poco conocidas. Nuestro objetivo es presentar la clasificación establecida por João Barbosa Rodrigues (1842-1909), uno de los primeros a establecer un método para ordenar los registros arqueológicos en el Brasil. Desde 1875 hasta 1899, ello tuvo una posición singular y original en la arqueología brasileña, fuertemente influenciado por las teorías lingüísticas de Karl P. von Martius. 
Palabras-Clave: João Barbosa Rodrigues; Historia de la Arqueología Brasileña; Etnoclasificación

\begin{abstract}
The classification is a key task for Science, serving the most diverse aims. For archeology is one of the central tools to understand the content, form, meanings, spatial distribution, and the chronology of material culture. In the American continent, the paradigm of classification predominated until the 1940s. In Brazil, we can say that it prevailed until the late 1980's. The history of Brazilian archeology shows that different strategies for classification were adopted, almost all of them related to mid 19th century European and American schools. In Brazil, the reasons behind the chosen ways of classifying are still poorly known. This article presents João Barbosa Rodrigues' method of archaeological classification. From 1875 until 1899, he took a unique and original position within Brazilian archeology, heavily influenced by the systematic and by the linguistic theories of Karl P. von Martius.
\end{abstract}

Keywords: João Barbosa Rodrigues, History of Brazilian Archaeology, Ethnoclassification. 
A classificação é uma das principais tarefas da Ciência, servindo aos mais variados objetivos. Em Arqueologia, é uma das ferramentas centrais para a compreensão do conteúdo, da forma, dos significados, da distribuição espacial e da cronologia da cultura material. No continente americano, o paradigma classificatório predominou até a década de 1940 (Adams e Adams 1991: 333). Para Willey e Sabloff (1980: 7-9, 83), a História da Arqueologia divide-se, grosso modo, em dois períodos, assim nomeados: 1) classificatório-descritivo (1840-1914), com “ênfase na descrição sistemática dos vestígios arqueológicos e monumentos, e na classificação desses dados conforme as tipologias formais"; 2) classificatório-histórico (1914-1940), com o predomínio do interesse cronológico, a "história como ordenação temporal dos eventos". No Brasil, esses períodos ultrapassaram 1914 e 1940, com o classificatório-histórico dominando até o final da década de 1980.

A história da arqueologia brasileira revela a adoção de diversas estratégias de classificação, quase todas relacionadas às escolas estabelecidas na segunda metade do século XIX (Ferreira 2007). Contudo, as razões que levaram os pesquisadores a decidirem pelos métodos de classificação arqueológica no Brasil ainda são pouco conhecidas. Portanto, é necessário destrinchar a associação dessas escolhas aos temas e problemas de pesquisas de cada época. Conforme Shapin (1974), a institucionalização de uma ciência deve-se às políticas que definem os objetos a serem estudados e as formas possíveis de abordá-los me- todologicamente. Entendemos que essa perspectiva é crucial para a análise da História da Arqueologia no Brasil.

Neste artigo, nosso objetivo ${ }^{1}$ é apresentar as linhas gerais da classificação arqueológica estabelecida por João Barbosa Rodrigues (1842-1909), o primeiro a criar no Brasil um sistema para ordenar os registros arqueológicos a partir de etnoconhecimentos, especificamente na Amazônia. Entre 1875 e 1899, ele assumiu uma posição singular e original no âmbito da arqueologia brasileira, influenciando-se notadamente pela sistemática e pelas teorias lingüísticas de Karl P. von Martius. Já em suas primeiras publicações, Barbosa Rodrigues esteou-se numa perspectiva lingüística internacional, desenvolvida desde 1830 , segundo a qual as línguas, não obstante terem se modificado e se subdividido historicamente, poderiam ser reconstruídas em suas formas originais.

O legado de Barbosa Rodrigues para a Arqueologia e a Antropologia é praticamente ignorado. Ele é conhecido, sobretudo, pelo seu valioso e vasto trabalho como botânico. Vários cientistas, com unanimidade, destacam-no na Botânica (p. ex.: Mori e Ferreira 1987; Sá 2001), sendo, inclusive, considerado um dos grandes naturalistas do século XIX (Balée 1994:32). Estando entre os que inauguraram a arqueologia brasileira, definiu temas de pesquisa, propôs teorias, hipóteses e interpretações que perduraram até o século XX. Suas primeiras publicações, especialmente as de 1875-1876, fixaram sua abordagem e apresentaram uma impressionante quantidade de idéias amadurecidas no 
exercício entre a teoria e a prática. Barbosa Rodrigues foi a campo preparado, fundamentado na Arqueologia e Antropologia desenvolvidas na Europa e Estados Unidos (Ferreira 2007). Contudo, como arqueólogo e antropólogo, não foi unanimidade. De um lado, criticaram-no duramente por seus estudos sobre os muiraquitãs (p. ex.: Romero 1888) e por algumas das suas teorias extremamente idealizadas na lingüística Tupi (p. ex.: Edelweiss 1969: 202204). De outro, reconheceram o valor de suas contribuições, considerando-o como "eminente sábio" e autor de teorias “ousadas” (Ihering 1911: 23). Recentemente o valor das suas idéias para a Arqueologia da Amazônia foi ressaltado por Roosevelt (1991). Contudo, posições favoráveis ou contrárias não devem apagar as contribuições de Barbosa Rodrigues para a Arqueologia.

\section{OS FUNDAMENTOS DA ARQUEOLOGIA DE BARBOSA RODRIGUES}

Barbosa Rodrigues pesquisou a taxonomia e a classificação indígenas ao longo da sua carreira, em busca de dados para identificar plantas, animais, elementos naturais e artefatos. Não alterou sua perspectiva por trinta anos, seguindo duas linhas de pesquisa. A primeira foi a da sistemática ou classificação científica. A segunda assentava-se na teoria de que o tupi, que ele chamava de abanheenga, era a matriz da maioria das línguas indígenas faladas no Brasil. Tais pressupostos definiram seu método para ordenar e interpretar os dados arqueológicos e de outras áreas de interesse antropológico, como a etnografia, a mitologia e a lingüística. No caso da botânica associada à lingüística, conseguiu estabelecer no seu último livro, em 1905, o sistema etnobotânico do "abanheeng", também "conhecida por Tupi ou Karani"” (Barbosa Rodrigues 1905: 19). $\mathrm{Na}$ sua melhor definição dessa língua, considerava que "uma grande nação, dividida em hordas, com diferentes nomes... falava uma só língua, o abanheenga ou nhengatú, a língua do índio, a língua boa, à qual os primeiros colonos deram o nome de geral" (Barbosa Rodrigues 1890: vi).

A perspectiva antropológica de Barbosa Rodrigues não resultou apenas de seu gênio criativo. A análise de sua obra revela que ele balizou-se nos princípios dos institutos a que era associado e, especialmente, em algumas teorias de Martius. Também foi influenciada pelo contexto intelectual do Rio de Janeiro, que proporcionava atividades no campo antropológico. Figuras destacadas, como Couto de Magalhães (1873, 1935 [1876]: 288), convocavam "nossos homens de talento", aqueles "que se sentem com vocação para este ramo de conhecimento" para "aprender o tupi”. As amizades também foram importantes na sua formação científica. Dentre os seus amigos, podemos mencionar Francisco Freire Alemão, Gustavo Capanema, Batista Caetano, Custódio Alves Serrão e Salamon Eberhard Henschen.

A formação acadêmica de Barbosa Rodrigues ocorreu na Escola Central de Engenharia no Rio de Janeiro, onde se graduou aos 25 anos. Sua formação em Arqueologia e Antropologia é difí- 
cil de ser rastreada nas fontes disponíveis. Até o presente não existe menção explícita sobre onde estudou ou quem lhe orientou. A pista mais provável aponta para seus amigos Gustavo Capanema e Freire-Alemão, responsáveis pela criação da seção de arqueologia e etnografia do IHGB (Ferreira 1999). Além deles, o autodidatismo deve ter levado Barbosa Rodrigues a consultar com freqüência as bibliotecas cariocas, como a do IHGB, que recebiam anualmente livros e periódicos arqueológicos e antropológicos. Indiretamente, porém, é possível verificar a fundamentação teórica e metodológica explícita nas suas publicações, marcadas por uma orientação atualizada em relação ao que de melhor a Arqueologia havia produzido até então.

\section{A INFLUÊNCIA DAS INSTITUIÇÕES CIENTÍFICAS EM BARBOSA RODRIGUES}

A comparação entre a obra de Barbosa Rodrigues e os estatutos de algumas das instituições em que ele foi sócio, mostra alguns de seus fundamentos, especialmente a escolha dos temas de pesquisa e a classificação da cultura material indígena. Merece destaque o Instituto Histórico e Geográfico Brasileiro (IHGB), sediado no Rio de Janeiro, que reunia a maioria dos cientistas atuantes no país e pautava a pesquisa em geral.

As idéias arqueológicas e antropológicas estavam em rede em meados do século XIX, formando um campo científico articulado a partir de universidades e instituições internacionais, nacionais e regionais ${ }^{3}$. Desde a sua fundação em 1838, o IHGB considerou a Arqueolo- gia entre as suas tarefas de debate, pesquisa e intercâmbio com instituições congêneres estrangeiras, integrando-se no processo de mundialização da ciência (Ferreira 1999, 2002, 2006, 2007). A Arqueologia estava atrelada à antropologia, onde os temas indígenas também eram pauta desde os primeiros dias do Instituto. $\mathrm{O}$ número um da revista do IHGB, de 1839, destacava a temática indígena e a necessidade da sua classificação no artigo Lembranças do que devem procurar nas provincias os sócios do Instituto Histórico Brasileiro, para remeterem à sociedade central do Rio de Janeiro. Seu autor, Januário da Cunha Barbosa (1839:141-143), fez solicitações que especificaram os estatutos do IHGB, pedindo por "notícias sobre os costumes dos índios, sua catequese, civilização, seu número presumível, sua indústria...". Também pedia por "notícias sobre seus minerais, animais, aves, peixes, etc, acompanhadas, se possível for, da nomenclatura científica... também de suas madeiras de construção, plantas particulares..., frutos mais preciosos, bálsamos e óleos, e do seu emprego na medicina”. Em 1847, após anos de debate, alguns sócios propuseram a criação da Seção de Arqueologia e Etnografia Americana (Ferreira 1999). Em 1851, o novo estatuto atualizou as perspectivas institucionais seguindo o avanço da ciência e seu primeiro artigo definia claramente que o IHGB: "tem por fim coligir, metodizar, publicar, ou arquivar os documentos concernentes à história e geografia do Império; e à arqueologia, etnografia e línguas de seus indígenas". Na década de 1880 , Barbosa Rodrigues integrou a Comis- 
são de Arqueologia e Etnografia do IHGB (RIHGB 44: 545).

A Sociedade Velosiana, criada em 1850 para operar no campo das ciências naturais, foi outra instituição em que Barbosa Rodrigues foi sócio (Sá 2001). Ela tinha por objetivo: "indagar, coligir e estudar todos os objetos pertencentes à história natural do Brasil; e juntamente averiguar e interpretar as palavras indígenas, com que forem designados".

Barbosa Rodrigues seguiu princípios semelhantes quando fundou, em 1883, o Museu Botânico do Amazonas, com uma seção de Etnografia e Arqueologia (Ferreira 2007). A seção era ordenada segundo o plano de pesquisa formulado por Barbosa Rodrigues, aprovado pela Lei Provincial do Amazonas n. 629, de 18/06/1883 (Porto 1892: 62). Quando publicou e editou em 1888 (reedição em 1891) o primeiro número da revista Vellosia, escreveu no prólogo que era necessária a presença da Etnografia (onde incluía a Arqueologia) ao lado das pesquisas das ciências naturais: "ocupando-se... não só das leis, costumes, usos, traços físicos e origens de um povo, mas também da sua língua, da sua religião e dos seus mitos" (Barbosa Rodrigues 1891: viii).

\section{A INFLUÊNCIA DA SISTEMÁTICA E DE KARL P. VON MARTIUS EM BARBOSA RODRIGUES}

Se as instituições influenciaram na escolha dos temas de pesquisa, a sistemática científica e algumas teorias e idéias gerais de Karl P. von Martius deram a estrutura analítica e parte da metodologia da obra antropológica e arqueo- lógica de Barbosa Rodrigues. Evidentemente, percebem-se outras influências mais específicas, como Batista Caetano no tratamento das palavras indígenas e Charles Hartt na forma de apresentar a cosmologia. Hartt e Couto de Magalhães também parecem ter inspirado Barbosa Rodrigues no método de coletar os dados etnográficos, valorizando a pesquisa de campo e o informante.

De todo modo, Martius norteou decisivamente a pesquisa arqueológica e antropológica no Brasil (Ferreira 1999). Entre 1838 e 1867 propôs, sem nunca alterá-las, teorias e hipóteses que embasaram a lingüística indígena no Brasil do século XIX, sobretudo a teoria da língua tronco, de onde derivavam todas as demais. Ele trabalhou no problema após sair do Brasil, onde viajou entre 1817 1820 com Johann von Spix, apresentando-o em seu primeiro trabalho sobre a "língua Tupi" em 1838. Em 1867, em seu clássico livro Contribuição à Etnografia e à Lingüistica Americanas, estabeleceu que entre os problemas de pesquisa que a "população primitiva da América oferece à Antropologia e Etnografia, um dos mais pesados é a inumerável multidão de idiomas e dialetos, e a redução deles à certas linguagens principais e quase fundamentais" (Martius 1867: xiv). Em sua palestra de 1838, intitulada como $O$ Passado e o futuro do Homem Americano, já dizia que "não deixa de ter fundamento a hipótese de derivar este imenso número de línguas e dialetos americanos de algumas poucas línguas originais" (Martius 1905 [1838]: 545).

Para Martius, estas perspectivas seriam possíveis com a pesquisa sistemática nos 
moldes das ciências naturais. Propunha que "formando um elenco de plantas, animais e lugares neste mesmo idioma tupi, em grande parte explicados ou reduzidos à sistema, espero render serviço não somente aos naturalistas e geógrafos mas também a todo brasileiro, que quiser estudar a condição dos antigos donos do país e conhecer os nomes sistemáticos da ciência correspondentes aos vulgares" (Martius 1867: xiv). Suas tentativas de "reduzir à sistema" foram publicadas diversas vezes, tanto na Flora Brasiliensis, quanto em obras variadas. Por exemplo, em cartas ao IHGB, dizia dedicar-se a dois objetos de pesquisa, "que também preenchem os fins do Instituto, a saber: história natural do reino vegetal do Brasil, e a história dos seus primitivos habitantes" (Martius 1840: 401). No Sistema de matéria médica vegetal brasileira, publicado em latim (1843 - traduzido para o português em 1854), escreveu que "as denominações índias com que são apelidadas as plantas medicinais brasileiras, derivam-se pela máxima parte da língua desse povo tupi, mas diferem muito umas das outras por causa da variedade de dialetos" (Martius 1854: 21). Em Como se Deve Escrever a História do Brasil, Martius (1844: 400) recomendava os estudos lingüísticos e a feitura de um dicionário sobre as línguas indígenas, especialmente o Tupi, e que servisse de modelo "o vocabulário que a Imperatriz Catarina mandou esboçar para as línguas asiáticas, e que afinal e principalmente se coligissem em primeiro lugar todos os vocábulos que referem a objetos naturais, determinações legais, (de direito) ou vestígios de relações sociais". Em outro livro, publicado em alemão em 1844, Natureza, doenças, medicina e remédios dos indios brasileiros, asseverou que os nomes das plantas "místicas ou pré-históricas", "como todos os produtos naturais, em muitas línguas, de certo modo [eram] considerados como principais ramos do tronco da língua americana" (Martius 1939 [1844]: 239). No Glossário de diversas línguas e dialetos que falam os indios no Império do Brasil, de 1867, apresentou extenso dicionário multilíngüe para exemplificar a sua sistematização lingüística (Martius 1867). Dois dos principais representantes e sócios do IHGB adotaram o paradigma da língua original e os estudos sistemáticos propostos por Martius. Couto de Magalhães reuniu em 1876, no livro $O$ Selvagem, a síntese de suas investigações da década anterior. Para ele, "nenhuma língua primitiva, nem mesmo o sânscrito, ocupou tão grande extensão geográfica como o tupi e seus dialetos" (Couto de Magalhães 1935 [1876]: 38). Batista Caetano, também em 1876, advogava pela redução às línguas fundamentais. Para ele, "na realidade o guarani não se diferencia do tupi senão tanto quanto o português falado pelos nascidos na Europa difere daquele que fala-se no império americano" (Nogueira 1876a: 3).

\section{O MÉTODO \\ DE BARBOSA RODRIGUES}

Classificar sistematicamente não era sugestão exclusiva de Martius. Era um dos principais objetivos dos cientistas do século XIX (Mayr 1971), estando no âmago das teorias antropológicas (Harris 1968) e dos padrões de classificação em Arqueologia (Goodrum 2002). E Isso justamente na época que Barbosa Rodrigues teve sua formação científi- 
ca, quando os arqueólogos travavam uma "luta para fazer da arqueologia uma disciplina científica e sistemática" (Willey e Sabloff 1980: 34). Foi quando a Arqueologia e a Antropologia viram nascer suas linhas mestras, no período Classificatório-Descritivo (1840-1914, com as obras de Darwin, Charles Lyell e John Lubbock. Estes trabalhos apoiaram-se em inúmeras teorias e empirias acumuladas na primeira metade do século XIX, a partir de pesquisas arqueológicas realizadas na Europa, Estados Unidos e outras partes do mundo (Daniel 1950; Groenen 1994; Stiebing 1993; Willey and Sabloff 1980; Trigger 2006). Para Harris (1968: 144), esse contexto resultava de uma "linha contínua de crescimento gradual do rigor das normas" da Antropologia (incluindo a Arqueologia), demonstrando que entre 1750 e a década de 1960 não ocorreu "nenhuma ruptura brusca na qualidade e quantidade dos conhecimentos etnográficos". O mesmo concluiu Trigger (2006: 10), afirmando que na história do pensamento arqueológico as mudanças foram graduais, sem estagnações radicais ou transformações repentinas.

O método de Barbosa Rodrigues procurou estabelecer um "arranjo tipológico" de todos os elementos culturais, atribuindo o mesmo valor aos dados arqueológicos e etnográficos (Ferreira 2007). Comparava o desenvolvimento tecnológico e artístico das formas dos artefatos: dos pares classificados como tipos técnico-funcionais semelhantes, mas também dos tipos classificados como antitéticos. Uma abordagem comparativa sobre as gradações formais e estilísticas que acompanhavam um mesmo artefato entre diferentes etnias. Princípio, pois, da continuidade tipológica, um modelo de arranjo e classificação de artefatos típico do final do século XIX. Ele seguia a tendência do momento, resumida por Lubbock (1865: 335): "apesar de nosso conhecimento sobre os tempos antigos ter aumentado muito nos últimos anos, permanece muito imperfeito e não podemos nos dar ao luxo de negligenciar qualquer fonte possível de informação".

A diferença e, para nós, a grande relevância do trabalho de Barbosa Rodrigues, foi a tentativa de rastrear os significados nativos para definir taxonomia e funcionalidade dos registros arqueológicos e etnográficos, de forma semelhante às pesquisas etnobiológicas da segunda metade do século XX. Essa busca objetiva foi a marca de uma conduta científica e de uma posição ideológica diferenciada no meio acadêmico da época, bem menos eivada de racismo se comparada às publicações de seus contemporâneos. A perspectiva evolucionista de Barbosa Rodrigues era mais dirigida para analisar o desenvolvimento tecnológico, dando pouco espaço para o racismo científico da segunda metade do século XIX. Tanto é assim que Barbosa Rodrigues, ao final da sua vida, criticou acidamente a perspectiva que seus colegas tinham dos povos indígenas: "a falta de inteligência, a falta de brio e de honra, a sua pouca atividade, que lhes lançam em rosto os escritores, no que o vulgo aliás acredita, não são mais do que véus que encobrem muitos crimes, e, para se justificar o procedimento bárbaro dos que se dizem civilizados" (Barbosa Rodrigues 1905: i) 
A precisão era o aspecto central do método de Barbosa Rodrigues, plenamente alinhado aos princípios do período classificatório-descritivo. Para ele, "a arqueologia é hoje uma ciência, por isso nela tudo deve ser exato e preciso; os nomes criados para seus monumentos devem perfeitamente caracterizá-los" (Barbosa Rodrigues 1880b: 60). Tal perspectiva e rigor sistemáticos foram adotados nas suas primeiras publicações sobre arqueologia. Simultaneamente, um segundo aspecto relevante do método é a circunscrição geográfica do registro arqueológico, tão importante para a sistemática quanto o rigor descritivo. Para Barbosa Rodrigues (1876a: 104), “a importância que ligo aos lugares de onde saíram estes instrumentos, me levam a mencioná-los sempre". Todas as suas descobertas arqueológicas estão contextualizadas geograficamente e descritas em suas publicações sobre arqueologia e nas explorações dos rios Jamundá, Capim, Urubú, Jatapú, Tapajós e Jauperí.

A analogia é outro aspecto relevante da sistemática que reforçou o método de Barbosa Rodrigues desde suas primeiras publicações, denotando que foi para campo preparado para praticar Arqueologia e Etnografia. Ele formulou um pressuposto que resume sua perspectiva para observar, abordar, analisar e interpretar suas descobertas: "como na geologia, na etnografia, os fatos modernos nos explicam os antigos" (Rodrigues 1876a: 102), adaptando um conceito da geologia, o uniformitarismo, originário do iluminismo escocês e difundido por Charles Lyell: the present is the key to the past (o presente é a chave do passado). Barbosa Rodrigues adotava uma linha de pensamento em voga ao redor de 1870, de que a arqueologia formava um "elo entre a geologia e a história” (Lubbock 1865: 2). A analogia abriu o caminho do método para estabelecer a taxonomia nativa do registro arqueológico, usando nomes do presente para classificar elementos do passado. Não era propriamente uma justificativa para definir exclusivamente a cronologia, elemento secundário na sua abordagem. Servia para refletir sobre a "antiguidade" como instrumento analítico para determinar a origem, a continuidade, mudança e diferenciação cultural. Essa perspectiva levou-o à interpretação de que havia continuidade e reprodução cultural ao longo do tempo, fator essencial para aceitar e ampliar o escopo da teoria lingüística de Martius sobre redução da heterogeneidade lingüística em princípios homogêneos fundamentais.

Vale à pena reproduzir algumas idéias que Barbosa Rodrigues formulou em 1876, a partir de suas observações de campo e das leituras de Arqueologia e Etnografia:

"como [os indígenas] distinguiremse uns dos outros se, a avaliarmos pelos costumes modernos, que só nos guiam, os gentios não dão um passo sem serem imitativos? O progresso não existe entre eles, por conseguinte a alteração da forma não aparece senão quando há um modelo. A forma de seus instrumentos é sempre a mesma; não tendo eles senão a deixada pelos seus antepassados não podiam modificá-la, visto ser índole desse povo não fazer mais do que imitar, como que respeitando a herança 
dos seus avoengos" (Barbosa Rodrigues 1876a: 102).

Da mesma forma pensava, em 1892, que: "os índios... não sabem o que é progresso e fielmente respeitam os costumes de seus maiores. Tudo quanto fazem segue os modelos primitivos, o que é de grandes vantagens para o etnólogo, porque, desse modo, quem conhece seus hábitos pode distinguir uma tribo de outra. Seus enfeites, suas cerimônias, suas festas, seus atos fúnebres são sempre conservados com religiosa fidelidade" (Barbosa Rodrigues 1892: 6).

O progresso era entendido como sinônimo de mudança e evolução, como motor da variabilidade cultural. Contudo, Barbosa Rodrigues e os pesquisadores que lhe eram coetâneos percebiam os indígenas como marcados e moldados pela uniformidade cultural, vista como o "seguir modelos primitivos". O registro da cultura material etnograficamente observada era considerado similar ao registro arqueológico, mesmo que muitas vezes os elementos do presente fossem entendidos como uma versão empobrecida dos elementos do passado. O mesmo ocorria na cosmologia. Por exemplo, comparando a Amazônia com o contexto alemão, Barbosa Rodrigues (1881: 24) escreveu que "quase sempre o mito origina a lenda" e que "as lendas entre todos os povos são a tradição viva do pensamento primitivo e o desenvolvimento intelectual das épocas de sua origem". Esta perspectiva, como analisaremos futuramente (Noelli e Ferreira s/d), levou Barbosa
Rodrigues à crença na degeneração cultural e à defesa de uma hipótese sobre empobrecimento lingüístico ocorridos após o contato com os europeus.

A precisão taxonômica, posição geográfica e analogia entre presente e passado orientavam os principais fundamentos metodológicos das pesquisas de Barbosa Rodrigues. Ali começava outra faceta do seu método de classificação, que era a coleta de dados lingüísticos para definir taxonomia e função do registro arqueológico. A metodologia de campo, descrita na sua primeira publicação arqueológica em 1876, revela os detalhes de um autêntico naturalista do século XIX:

\begin{abstract}
"com o lápis na mão... não retratava só as flores; no meu caderno de campo, a par de uma descrição botânica, muitas vezes deixava também estampado um objeto que do seio da terra extraía. Sempre o que dizia a respeito aos habitantes das florestas, quer os d'outrora quer os de hoje, me chamava a atenção e uma nota especial merecia. Por insignificante que fosse o achado, sempre dava lugar a um estudo, a uma comparação e uma análise" (Rodrigues, 1876a: 94).
\end{abstract}

A nota especial alude ao contínuo interesse de Barbosa Rodrigues pela busca de informações entre indígenas e caboclos, para sua compilação de taxonomia e função de plantas, cultura material, cosmologia, comportamentos e técnicas. Desde os seus primeiros relatórios sobre as explorações amazônicas, entre 1874 e 1875, reiterou a importância das entrevistas realizadas, sobretu- 
do, com "velhos" e informantes mais qualificados para localizar elementos do seu interesse (p. ex.: Barbosa Rodrigues 1875a: 57-58; 1875b: 7, 1885:141, 149). O mesmo ocorreu nas publicações de arqueologia. Mas foi nas obras lingüísticas que destacou a importância da pesquisa sistemática pela informação etnográfica e o respeito pelo informante. Na Poranduba Amazonense, portentosa coletânea de cosmologias, disse que "coligiu notas preciosissímas dos falares dos índios com os quais tratou" (Barbosa Rodrigues 1890: ii). Na introdução do Vocabulário indígena comparado para mostrar adulteração da língua, declarou que "procurei sempre ouvir os maiores de sessenta anos, e com muitas velhas e velhos maiores de cem anos me entendi. Em geral esses velhos não falam quase o português" (Barbosa Rodrigues 1891: 1). No seu último livro, de 1905, declarou sua profissão de fé no trabalho de campo, sublinhando que: "foi entre pajés e vaqueanos, colhendo plantas e flores, e ouvindo e praticando a língua [geral], no norte, no centro, e no sul do Brasil, e não no gabinete folheando vocabulários, mal escritos, mal interpretados pelas impressões e mal corrigidos pelos revisores" (Barbosa Rodrigues 1905: i).

A comunicação com essas pessoas era em língua geral. Não há informação de quando Barbosa Rodrigues aprendeu esse idioma. Declarou que o falava desde 1874 (Barbosa Rodrigues 1875a: 21) e que sempre procurou reunir dados em línguas indígenas, "como simples amostra" (Barbosa Rodrigues 1890: 210). Em 1885 publicou A Pacifi- cação dos Crichanás, enfatizando que sua habilidade na língua geral salvou sua equipe do massacre e possibilitou, por conseguinte, a "pacificação" daqueles indígenas do rio Jauperí (Barbosa Rodrigues 1885: 46-58). É provável que tenha aprendido a falar a partir de sua chegada ao Amazonas em 1873. Pode ser também que já dominasse a língua antes, por causa da nomenclatura botânica brasileira dominada por uma taxonomia predominantemente tupi. Uma parte do meio intelectual carioca, liderada por Couto de Magalhães e pelo exemplo de D. Pedro II, pode ser outra pista. Existe ainda a possibilidade da influência do seu amigo Batista Caetano, maior lingüista brasileiro da época, de quem seguia a maneira de grafar as palavras indígenas, sobretudo a língua geral (Barbosa Rodrigues 1876a: 97). Por fim, talvez a soubesse desde o berço, tendo-a aprendido com sua mãe, descendente indígena (Mori e Ferreira 1987: 74).

Abordar indígenas e caboclos sem intérpretes não era uma novidade no Brasil. Mas a busca da precisão lingüística para a taxonomia passara a ser dever do naturalista, como indicam claramente os exemplos muito próximos de Batista Caetano, Couto de Magalhães e Charles Hartt. Pouco antes de Barbosa Rodrigues chegar ao Amazonas em 1873, Hartt (1872:61) aprendeu a língua geral com diversos indígenas entre 1870 e 1871, para escrever seu livro sobre a geologia do Brasil. Hartt relatou um método de estudos que pode ter servido de exemplo a Barbosa Rodrigues: "logo me tornei um tanto fami- 
liar com a linguagem, tomei dos lábios dos nativos centenas de frases para ilustrar a estrutura da língua; finalmente, habituei dois de meus guias a ditarem diálogos, histórias, lendas, fábulas, etc. Tudo era escrito exatamente como era ditado e cuidadosamente corrigido com auxílio do nativo uma e mais vezes" (Hartt 1872: 61; 1937: 309-310). Couto de Magalhães (1935 [1876]), além dos contatos com diversos grupos indígenas nas longas viagens pelo interior do Brasil, parece ter usado métodos semelhantes, quando identificou e usou como informantes inúmeros nativos falantes da língua geral, alistados nas forças imperiais.

Para Barbosa Rodrigues, o problema da incompetência lingüística na bibliografia científica era uma barreira a ser superada para melhor definir os elementos a serem classificados. Desde as suas primeiras publicações (Barbosa Rodrigues 1875a: 34) enfatizava a necessidade de coletar novos dados lingüísticos, uma vez que partilhava com Batista Caetano uma consideração negativa sobre as obras lingüísticas feitas desde o século XVI. Para eles havia várias causas, como a incompreensão lingüística gerada por estrangeiros que desconheciam o português e publicavam traduções erradas, alteravam a nomenclatura para adaptá-la à fonéticas de suas línguas maternas e outras várias deturpações das línguas indígenas, sem contar os erros tipográficos e documentos incompletos devido à deterioração (Barbosa Rodrigues 1875a: 34-35; 1905: i, Nogueira 1876a; 1876b). Apesar do contínuo esforço,
Barbosa Rodrigues não conseguiu superar os problemas que criticava. Um século depois, seu trabalho lingüístico foi considerado amador, por seguir rigidamente as categorias gramaticais européias e pela transcrição da língua geral baseada na ortografia do português, sem indicar separação de morfemas e deixando os prefixos escritos separadamente (Moore et al 1993).

Outro aspecto do método de Barbosa Rodrigues que merece destaque é a pesquisa das fontes escritas, tanto em busca de dados historiográficos, quanto pelo levantamento de dados arqueológicos, etnográficos e lingüísticos. Desde os seus primeiros relatórios de 1875, é explícito o uso das fontes para contextualizar aspectos diversos da pesquisa, para sistematizar dados sobre a paisagem, a botânica, a toponímia, as sociedades, a economia, a cultura material e a história indígena. Por exemplo, decidiu explorar o rio Jamundá inspirado no relato de Francisco Orellana sobre as "Amazonas", além de investigar temas de economia regional e História Natural (Barbosa Rodrigues 1875b: 4). O tema dos muiraquitãs também surgiu em função da pesquisa histórica associada aos seus próprios achados e aos de Martius (Barbosa Rodrigues 1875b, 1875d, 1889, 1899), em publicações arquitetadas sobre enorme quantidade de dados das Américas, Ásia e Europa, sistematizados e comparados para fundamentar sua teoria da origem asiática dos famosos "ídolos amazônicos". A teoria criou grande polêmica desde a sua publicação em 1875, a ponto de eclipsar a compreensão do conjunto das 
pesquisas, propostas e resultados obtidos por Barbosa Rodrigues, sobretudo seu rigoroso método de investigação. A quantidade de fontes que citou revela uma erudição ímpar, sobretudo pelo olhar capaz de identificar e extrair informações úteis ao arqueólogo. $\mathrm{O}$ volume de referências e citações foi tão exaustivo nos livros sobre os muiraquitãs, que seus críticos chegaram a chamar Barbosa Rodrigues de autor de "impertinentes compilações” (Romero 1888: 83).

No balanço que fez do conjunto da sua obra em 1899, no segundo volume do livro O muyrakytã e os ídolos simbólicos, tratou do esforço para obter resultados. Disse ter:

"como lema científico que só a abnegação, a experiência e a prática nos podem fazer chegar a verdade, neste último quarto de século, tenho-me ocupado em desvendar o passado dos nossos silvícolas... Nada tenho desprezado e daí uma série de viagens e estudos práticos arqueológicos, etnográficos, lingüísticos e antropológicos. Não desprezei o folclore, e... as lendas indígenas (Barbosa Rodrigues 1899 2: v).

De certo modo, repetia uma idéia do início da carreira. Em 1875 fez uma interessante declaração sobre a pesquisa arqueológica interdisciplinar e do seu alcance científico e público:

"caminhe o arqueólogo e sorria-se do indiferentismo, porque só ele, reunindo os numerosos monumentos de uma civilização extinta que aí estão disseminados, pode, unido depois ao paleógrafo, decifrar essas inscrições, e com esses monumentos e os radicais das línguas modernas dos nossos índios, levantar o véu que encobre o mistério da aparição do homem americano" (Barbosa Rodrigues 1875b: 95).

A abordagem sistemática, a definição de problemas de pesquisa e a ordenação rigorosa dos dados permitiram resultados que distinguem Barbosa Rodrigues como arqueólogo integrado ao movimento científico internacional. Infelizmente sua perspectiva foi abandonada. Ele foi um precursor daquilo que pouco tempo depois seria chamado como o trabalho dos "quatro campos" da antropologia. Quando Barbosa Rodrigues publicava seus últimos trabalhos, Franz Boas (1902: 1) declarava que: "é impossível compreender o significado dos vestígios arqueológicos americanos sem o recurso da observação etnológica, que freqüentemente explica o significado das descobertas pré-históricas".

Seu resultado antropológico mais significativo foi reconhecer a existência do sistema etnobotânico entre os falantes das línguas do tronco tupi, no livro Mbaé kaá tapyiyeta enoyndua ou a botânica e a nomenclatura indígena, de 1905. Este trabalho, feito a partir da agregação e normatização de dados lingüísticos de várias regiões do Brasil, foi o precursor de um tema de pesquisa contemporâneo, que Balée (2000) recentemente chamou de "conhecimento etnobiológico tradicional", que revela antiguidade e reprodução de conhecimentos entre os falantes das línguas Tupi-guarani. A perspectiva interdisciplinar de Barbo- 
sa Rodrigues, especialmente lastrada na etnografia e na botânica, permitiu a compreensão densa e profunda do seu tema antropológico mais caro, herdado de Martius - a origem e a diferenciação dos povos Tupi, a continuidade e as mudanças culturais. Barbosa Rodrigues e os demais estudiosos do tema no século XIX atuaram muitas décadas antes da compreensão definitiva de que havia um tronco lingüístico composto por famílias que agrupavam várias línguas e dialetos. Mesmo assim, ele conseguiu resultados surpreendentes ao concluir sobre a existência de estruturas de conhecimento que eram constantes, a exemplo da Botânica e da nomenclatura da cultura material. Barbosa Rodrigues realizou uma comparação do sistema que identificou entre os indígenas com mais de 40 sistemas, desde Teofrasto, passando por Lineu, Lindley, Bentham, Hooker e Engler (Barbosa Rodrigues 1905: 11-17). Duas de suas conclusões merecem citação:

"os índios agrupam as espécies em gêneros e conhecem perfeitamente a utilidade do sistema binário, sem contudo o terem aprendido do velho sábio sueco... $\mathrm{Na}$ taxonomia os nomes que eles dão às espécies vegetais traduzem muitas vezes bem melhor os caracteres das mesmas, que aqueles escolhidos pelos discípulos de Lineu" (Barbosa Rodrigues 1905: 10).

"não é para censurar o sistema natural que empregam os selvagens, porquanto filósofos considerados notabilidades na ciência e tornaram imorredouros os seus nomes à força do estudo, organizaram sis- temas ou métodos botânicos, alguns inferiores e menos racionais do que os dos nossos indígenas" (Barbosa Rodrigues 1905: 11).

Não chegou ao mesmo nível de sistematização para a cultura material. Contudo, lançou as bases para que fosse possível compreender que havia um estilo tecnológico estruturalmente estabelecido entre os povos Tupi, com taxonomia, funcionalidade e conteúdos formais regularmente definidos e reproduzidos. A etnoclassificação de Barbosa Rodrigues foi pragmática e ideológica, na época que havia um debate normativo sobre "língua Tupi", pautado por uma perspectiva idealizada. A normatização em busca da legitimidade, segundo Barros (1990), foi marcada pela "transposição dos ideais românticos para o interior dos estudos lingüísticos". Operava-se em torno do que era considerado legítimo/ilegítimo, correto/incorreto, falso/verdadeiro, exato/adulterado, a partir das variações da teoria da degeneração (Noelli e Ferreira 2007).

$\mathrm{Na}$ prática, seu objetivo era propor termos que expressassem conceitos indígenas específicos para denominar o registro arqueológico. Sob essa perspectiva, Barbosa Rodrigues não era um determinista. Lança desde cedo a noção de que o registro arqueológico poderia mostrar diferenças tipológicas que "pela comparação de uns com outros, poder-se-á ver a subdivisão da raça, com as modificações que fizeram nos seus usos, representados em seus instrumentos, e por um estudo comparativo e analítico chegar a poder fazer- 
se um juízo sobre a sua origem" (Barbosa Rodrigues 1876a: 104).

\section{CONCLUSÃO: OS RESULTADOS DE BARBOSA RODRIGUES}

A etnoclassicação de Barbosa Rodrigues foi estabelecida para definir um conjunto específico do registro arqueológico, dividido "em armas, instrumentos e ídolos de pedra, louça de uso doméstico e aterros, sernambys ou kjokkenmöddings, urnas mortuária (ygasáuas) e em inscrições ou desenhos [rupestres]" (Barbosa Rodrigues 1876a: 101). Considerando apenas os itens de interesse arqueológico, verificamos que ele procurou a taxonomia para contexto arqueológico, artefatos líticos e recipientes cerâmicos (onde incluímos dados sobre cores, pigmentos e técnicas de decoração nos Quadros 1, 2 e 3). Também consideramos alguns artefatos de madeira que poderiam ser feitos com rochas, como o pilão e a mão de pilão, e o ralador, cuja prancha de madeira recebia incrustações de pequenas lascas líticas que podem ser encontradas nos sítios arqueológicos. Evidentemente, omitimos uma lista muita mais vasta de cultura material, notadamente os artefatos feitos com componentes orgânicos, amplamente estudados por Barbosa Rodrigues em seus textos e dicionários. Não a incluímos devido ao curto espaço disponível para este artigo.

Apenas a taxonomia (sem tratamento fonético) e suas definições serão apresentadas, deixando para outra publicação a apresentação e a análise das interpretações arqueológicas de Barbosa Rodrigues (Noelli e Ferreira s/d). Por elas serem extensas e complexas, não gostaríamos de demonstrá-las de forma resumida e ensaística, por entendermos que vale à pena pormenorizá-las com citações, revelando a consistência e a erudição da sua perspectiva arqueológica. Ele utilizou terminologias da Língua Geral, Nheengatú, Avaeenga e, eventualmente, de outras línguas, para definir o nome e a função dos contextos arqueológicos (Quadros 1, 2 e 3). A grafia é variável por dois motivos. $\mathrm{O}$ primeiro deve-se ao fato de Barbosa Rodrigues tratar de línguas e dialetos distintos (quando possível, especificamos o caso: $\mathrm{Av}=$ avaeenga; $\mathrm{Nh}=$ nheegatú; LG = língua geral). O segundo, por causa de variações devidas às distintas formas em que ele representou a fonética, a exemplo de igasáua, igaçáua, igasava, igassava.

\section{1) Contexto Arqueológico}

$\mathrm{Na}$ maioria das vezes ele analisou o significado dos termos, explicando a composição e agregando sua análise interpretativa, como é o caso de sernamby e mirakangüera. Sernamby, termo que achava correto para definir sambaqui (Barbosa Rodrigues 1880a: 25-26), tinha para ele o significado de montes de concha, de "restos da vazante" que resultavam de ação humana, ao contrário dos seus contemporâneos, que entendiam a tradução como "orelha de caranguejo". Mirakangüera foi traduzida como necrópole, o superlativo do cemitério indígena comumente considerado sítio arqueológico (este definido como tanaquera). Desde o relatório Exploração aos rios Urubu e Jatapu (Barbosa Rodrigues 1875a), sua abordagem 
e método descritivos, a partir da observação das evidências in situ e da nomenclatura que anotava das populações locais, eram objetivas. Em geral, descrevia a geologia local, a inserção na paisagem, a estratigrafia, os aspectos externos dos sítios arqueológicos, a presença/ausência de terra preta, a dispersão/concentração dos fragmentos cerâmicos e líticos. Em geral... bem como discutia a funcionalidade dos sítios considerando as evidências de trabalho coletivo para construção de aterros, mounds e sambaquis (Cf. especialmente Barbosa Rodrigues 1892a). E, algumas vezes, com dados bibliográficos ou de história oral, reconstruiu aspectos da história do sítio arqueológico e dos seus ocupantes. Também usou esses dados somando-os às análises dos contextos arqueológicos e geológicos (local ou regional), para, então, refletir sobre a cronologia. Tais procedimentos aparecem desde os primeiros relatórios de exploração (1875a; 1875b; 1875c; 1885). Barbosa Rodrigues apresentou essa terminologia de forma completa e sistemática na série de artigos Antiguidades do Amazonas (1876a; 1876b; 1880; 1892a), nos livros sobre os muiraquitãs $(1889 ; 1899)$ e no Vocabulário indigena comparado (1892b). Sua interpretação às vezes extrapolava seus dados etnográficos e históricos, mas nunca longe do que pensavam seus contemporâneos, como é o caso do significado dos grafismos rupestres do rio Jauaperí, que considerou como o "local de repouso de um povo que emigrava, que, descendo as águas do rio Negro, deixava esses sinais para guia do tronco que thes sucedesse" (Barbosa Rodrigues 1885: 170).

\section{2) Lítico}

Os artefatos líticos formam o conjunto de "instrumentos e armas de pedra", que Barbosa Rodrigues afirmou ser "o primeiro que os estuda e descreve no Brasil" (Barbosa Rodrigues 1876a: 103). Considerava os artefatos líticos como "guias arqueológicos, que só dão luz à etnografia" (Barbosa Rodrigues 1876a: 120). Definiu-os como instrumentos "bem ou mal" polidos, divididos em "armas de guerra, utensílios de uso agrícola e doméstico e enfeites. Os primeiros compõem-se de massas, de pontas de flecha e de uma espécie

Quadro 1

Taxonomia dos contextos arqueológicos

\begin{tabular}{l|l|l}
\hline Táxon & Contexto Arqueológico & Fonte \\
\hline Mirakangüéra & $\begin{array}{l}\text { Osso de gente que existiu, de mirá = gente, } \\
\text { kang = osso, kuera = que existiu. Extenso } \\
\text { cemitério, verdadeira necrópole }\end{array}$ & BR 1892a: 2 \\
\hline Iuicuara & Sepultura (LG) & BR 1982b: 79 \\
\hline Iuicuar & Sepultura (Av) & BR 1982b: 79 \\
\hline Sernamby & "restos da vazante" & BR 1880a: 25 \\
\hline Sernamby & $\begin{array}{l}\text { Sery }=\text { carangueijo, namby }=\text { orelha, } \\
\text { literalmente orelha de carangueijo }\end{array}$ & BR 1880a: 26 \\
\hline Sernamby & Seryc $=$ vazante da maré, sembyr = restos & BR 1880a: 26 \\
\hline
\end{tabular}




\begin{tabular}{l|l|l}
\hline Taua & Aldeia & BR 1875a: 14 \\
\hline Tauaquera & sinais de uma extinta aldeia & BR 1880a: 17 \\
\hline Tauaquera & $\begin{array}{l}\text { fragmentos de louça que indicam nas terras } \\
\text { pretas a antiga aldeia }\end{array}$ & BR 1880b: 63 \\
\hline Tybyretá & Cemitério & BR 1880a: 10 \\
\hline Tybyretá & Cemitério & BR 1880b: 63 \\
\hline Yabakuaras & $\begin{array}{l}\text { Yabá }=\text { fugir, kuara = cova, caverna, gruta: } \\
\text { lugar em que se ocultavam os fugitivos }\end{array}$ & BR 1892a: 7 \\
\hline
\end{tabular}

folha de alabardes, e os outros, de machados, enxós, cunhas, mãos de pilão, mós, etc, e os últimos, de muiraquitãs" (Barbosa Rodrigues 1876a: 104). Posteriormente, a partir do sítio de Miracangüéra, repensou sua classificação geral e dividiu-os como "instrumentos de trabalho e não de guerra" e, aqueles considerados enfeites, passaram a ser definidos como "votivos" e "objetos de recordação, saudade e lembrança, ou amuletos garantidores de felicidade além túmulo, baetylias", para serem depositados com os mortos (Barbosa Rodrigues 1892a: 36, 37).

Ele achou "pontas de flecha de sílex, que são muito raras" e, também, cristal de quartzo. Fez considerações sobre a substituição dessas matérias pelas pontas de osso, de madeira e taquara (Barbosa Rodrigues 1876a: 106-108). Tratou, ainda, das "massas de pedra", nunca encontradas, substituídas pelas bordunas de madeira para combate corpo-a-corpo e para abater animais (Barbosa Rodrigues 1876a: 108-109). Os machados foram divididos entre os lascados, "toscos", que depois foram "aperfeiçoados" com o polimento. Entre os machados de Miracangüéra, criou uma tipologia com cinco tipos para trabalho e um tipo como artefato votivo (Barbosa Rodrigues 1892a: $37-$ 38). Dividiu-os entre "grandes, oblongos e cilíndricos", para o corte da madeira; "chatos e dos pequenos" para servir eventualmente de enxó. A tipologia variava conforme a função, incluindo a forma e tamanho presumíveis do cabo (Barbosa Rodrigues 1876a: 109110). Na cachoeira do Buburé, no rio Tapajós, encontrou oficinas líticas compostas por sulcos, que foram comparados ao formato do gume dos machados e serviram para deduzir como eram produzidos estes artefatos (Barbosa Rodrigues 1875c: 97). Baseando-se na observação de refugos arqueológicos, em deduções e na observação do trabalho de derrubada e queima, fez uma análise sobre a função e o desgaste dos machados (Barbosa Rodrigues 1875b: 92). Sobre os artefatos "votivos" e enfeites, especialmente os muiraquitãs, ele descreveu e fez uma prodigiosa quantidade de análises e interpretações (Barbosa Rodrigues 1875b, 1875d, 1876a 1889, 18991-2), dentre elas, os "ídolos" serviriam para a proteger os indígenas nas batalhas e pescarias.

\section{3) Cerâmica}

Foi o conjunto artefatual, pela quantidade e variedade de dados lingüísticos, 
etnográficos e arqueológicos, que foi tratado com maior detalhe por Barbosa Rodrigues (1876b, 1892a), onde analisa a cerâmica da Amazônia. O tamanho da taxonomia relativa à cerâmica que se apresenta abaixo, comparada com as do contexto arqueológico e do lítico, demonstra essa importância. Também, graças ao apelo estético das peças inteiras e dos fragmentos, altamente valo- rizados para integrar coleções de museus. Por fim, a análise ganhou maior consistência devido à sua presença entre as populações indígenas e caboclas que ele contatou na Amazônia, a maioria produtora de vasilhas cerâmicas. Ele observou a elaboração das peças e as várias funções a que serviam; recebeu inúmeros dados etnográficos e quase todas as suas análises e interpre-

Quadro 2

Taxonomia dos artefatos líticos

\begin{tabular}{|c|c|c|}
\hline Táxon & Contexto Arqueológico & Fonte \\
\hline Euêcé & $\begin{array}{l}\text { Ralador (prancha de madeira } \\
\text { com incrustações de lascas líticas) (Nh) }\end{array}$ & BR 1892b: 76 \\
\hline Euêcé & $\begin{array}{l}\text { Ralador (prancha de madeira } \\
\text { com incrustações de lascas líticas) (LG) }\end{array}$ & BR 1892b: 76 \\
\hline Iir & Machado (LG) & BR 1892b: 65 \\
\hline Induá & Pilão (Av) & BR 1892b: 78 \\
\hline Induá & Pilão (Nh) & BR 1892b: 78 \\
\hline Induá men & Mão de pilão (Av) & BR 1892b: 66 \\
\hline Induá Mena & Mão de pilão (LG) & BR 1892b: 66 \\
\hline Inuá & Pilão (LG) & BR 1892b: 78 \\
\hline Itapuá & Ita $=$ pedra, puá $=$ ponta $($ ponta de flecha $)$ & BR 1876a: 115 \\
\hline Muiraquitã & Muirá = pau, quitã = nó; ídolo, enfeite & BR 1876a: 120-121 \\
\hline Muiraquitã & Talismã ou amuleto & BR 1889: 29 \\
\hline Muiraquitã & $\begin{array}{l}\text { Vulgarmente se diz müyrá quitan, derivada } \\
\text { de mbyrá = madeira, pau, madeira, e kytã, } \\
\text { nó, pela semelhança que tem a verdadeira } \\
\text { jade, com as resinas }\end{array}$ & 1880b: 72 \\
\hline Tembetá & Pedra de pendurar-se no beiço & BR 1880b: 73 \\
\hline Tembetá & Adorno labial & BR 1889: 111 \\
\hline Uicé & $\begin{array}{l}\text { Ralador (prancha de madeira } \\
\text { com incrustações de lascas líticas) (Nh) }\end{array}$ & BR 1892b: 76 \\
\hline Yê & Machado (LG) & BR 1892b: 65 \\
\hline Yê, iê & Machado (Nh) & BR 1892b: 65 \\
\hline Yí & Machado (Av) & BR 1892b: 65 \\
\hline Yuecy & $\begin{array}{l}\text { Ralador (prancha de madeira } \\
\text { com incrustações de lascas líticas) (Av) }\end{array}$ & BR 1892b: 76 \\
\hline
\end{tabular}


tações derivam do que ouviu dos seus entrevistados. Seu artigo Antiguidades do Amazonas: Arte cerâmica (1876b), além de exemplo de descrição sistemática e da compreensão dos vários aspectos relativos à fabricação e uso do artefato, é um estudo precursor da etnoarqueologia. Ele é complementado pelo artigo Antiguidades do Amazonas: A necrópole de Mirakangüéra (1892a), onde avança na descrição das vasilhas, na análise funcional e na interpretação do significado etnográfico.

Barbosa Rodrigues dividiu as vasilhas em oito classes funcionais (definição na tabela 3): 1) Iukaçauas; 2) Kanguera reru; 3) Kamuci; 4) Kamuci uaçu; 5) Yaraki-çaua; 6) Kanguera-çaua; 7) Dauitibá; 8) Tykuçaua. Barbosa Rodrigues descreveu e mensurou as classes de vasilhas em diversas publicações, sempre procurando aperfeiçoar sua análise (Barbosa Rodrigues 1875b; 1876b; 1892a). Levantou a existência de vários problemas para definir sua interpretação, tanto pela observação dos exemplares arqueológicos, como pelas diferentes definições e classificações de funcionalidade nos exemplares etnográficos. Por exemplo, a classe do camotins, ele declarou que "sob este nome existem confundidos vasos com destino e formas diversas. Uns globulares, outros cilíndricos, os primeiros para guardar água e os seguintes para vinhaças" (Barbosa Rodrigues 1899 1:252). A definição funcional na cerâmica arqueológica no Brasil ainda é um campo aberto à investigação, tanto no caso Tupi (Noelli 2008), como nas demais tradições e conjuntos arqueológicos. Problema que se esten- de para a etnografia da cultura material, onde pouca pesquisa foi realizada em território brasileiro.

Descreveu as várias etapas de elaboração das vasilhas (Barbosa Rodrigues 1876b, 1892a), compondo um trabalho pioneiro sobre o tema no Brasil, que foi o mais completo até a década de 1940 , quando o Handbook of South American Indians apresentou vários capítulos sobre cerâmica arqueológica. Barbosa Rodrigues descreveu o uso de cauixi e caraipé como anti-plástico na cerâmica do médio Amazonas. Ainda deduziu, comparando exemplares arqueológicos e etnográficos, que os "mais antigos" usavam cauixi e os "mais modernos", atuais, agregavam caraipé (Barbosa Rodrigues 1875b: 90). A pintura foi um tema de interesse, que foi enriquecido pelos inúmeros dados etnográficos. $\mathrm{O}$ Quadro 3 mostra as quatro cores básicas (branco, vermelho, preto e amarelo), as matérias-primas e alguns verbos associados. A decoração ou tratamento de superfície recebeu atenção e Barbosa Rodrigues reconheceu "26 espécies de gregas", classificadas conforme a interpretação dos seus entrevistados, sobretudo no rio Jamundá. Contudo, ele não publicou o nome e o significado de todos os tipos decorativos (Barbosa Rodrigues 1875b: 89-91, 1876b, 1892a). Outro elemento importante no tratamento de superfície foi descrito, sendo composto por apliques antropomorfos e zoomorfos. Ele escreveu que "entre esta louça, encontram-se também muitas figuras, quer humanas quer de animais, que serviam para os brincos das crianças e não representam 
ídolos, como alguns querem" (Barbosa Rodrigues 1876b: 10).

Como exemplo, resumimos sua análise dos enterramentos nos contextos arqueológicos onde as cerâmicas são relevantes. A partir de peças inteiras e da "multidão" de fragmentos observados em Miracangüéra, Barbosa Rodrigues concluiu que três classes de igaçaba serviam como urnas funerárias. Elas tinham tamanho diversificado, que "indicam a estatura e a idade do indivíduo, o que se conhece pelo comprimento dos ossos, desde o adulto até a criança de peito" (Barbosa Rodrigues 1892a: 7).
$\mathrm{Na}$ primeira classe iam apenas os ossos, após a deterioração das carnes no solo: "guardavam-se provavelmente restos dos chefes, dos moakaras ou pessoas de família" (e de nível hierárquico mais elevado). $\mathrm{Na}$ segunda classe "encerravam-se restos do vulgo" (nível hierárquico mais baixo), com "ossos partidos após a cremação do corpo". Na terceira classe "encerravamse restos das cinzas das carnes e pó dos ossos" (Barbosa Rodrigues 1892a: 7).

Por fim, apresentamos o Quadro 3, onde está reunida a maior parte dos itens de interesse para o estudo da cerâmica, de acordo com Barbosa Rodrigues.

Quadro 3

Taxonomia relativa à cerâmica

\begin{tabular}{l|l|c}
\hline \multicolumn{1}{c|}{ Táxon } & \multicolumn{1}{c}{ Contexto Arqueológico } & Fonte \\
\hline Acutyranha & $\begin{array}{l}\text { Acuty }=\text { cotia, tanha = dente. Forma dois } \\
\text { apóstofres unidos (decoração) }\end{array}$ & BR 1876b: 17 \\
\hline Aryuauá & $\begin{array}{l}\text { Terra que contém partículas ferruginosas } \\
\text { de qualca, misturadas com vegetais para } \\
\text { formar pigmento preto }\end{array}$ & BR 1876b: 17 \\
\hline Cambycy & Pote (Av) & BR 1892b: 74 \\
\hline Camuti & Pote (LG) & BR 1892b: 74 \\
\hline Camutin & Pote (Nh) & BR 1892b: 74 \\
\hline Camuty & Pote (Nh) & BR 1892b: 74 \\
\hline Camuty & Pote (LG) 74 \\
\hline Caraipé & $\begin{array}{l}\text { casca moída de Moquilea utilis usada } \\
\text { como antiplástico }\end{array}$ & BR 1876b: 11 \\
\hline Cauichy & Espécie de esponja usada como antiplástico & BR 1876b: 11 \\
\hline Cuipéua & $\begin{array}{l}\text { Cui }=\text { cuia, péua }=\text { chata. Pedaço de cuia } \\
\text { ou uma concha usa para alisar a superfície } \\
\text { da vasilha em construção }\end{array}$ & BR 1876b: 15 \\
\hline Ecuy piranga & $\begin{array}{l}\text { Nome Aruak para panelas votivas em que } \\
\text { depositavam os víveres para o morto. } \\
\text { Ornadas de desenhos, por gravura ou pintura } \\
\text { e de emblemas zoomorfos e alguns } \\
\text { antropomorfos }\end{array}$ & BR 1892a: 14 \\
\hline Praia de argila vermelha & BR 1875b: 62 \\
\hline &
\end{tabular}




\begin{tabular}{|c|c|c|}
\hline Macauary & Xisto & BR 1875b: 75 \\
\hline Hiru & Vaso, vasilha (Av) & BR 1892b:82 \\
\hline Icica & Resina (Nh) & BR 1892b:77 \\
\hline Icica & Resina (LG) & BR 1892b:77 \\
\hline Icyg & Resina (Av) & BR 1892b:77 \\
\hline Igaçaua & Urna funérea & BR 1875a:95 \\
\hline Igaçaua & Pote de água $(\mathrm{Nh})$ & BR 1892b:74 \\
\hline Igaçauas & $\begin{array}{l}\text { Pequenos potes onde o pó da ossada humana } \\
\text { era colocada após o descarnamento }\end{array}$ & BR 1875a:53 \\
\hline Igaçava & Pote de água (LG) & BR 1892b:74 \\
\hline Igaçava & Pote de ossos (Nh) & BR 1892b:74 \\
\hline Igasáuas & Urnas mortuárias & BR 1876b:9 \\
\hline Igasáus & $\begin{array}{l}\text { Urnas funerárias, uso que logo deixaram } \\
\text { pela sepultura cristã }\end{array}$ & BR 1876a:95 \\
\hline Igasáus & $\begin{array}{l}\text { Urnas funerárias onde recolhiam } \\
\text { os ossos dos infelizes mortos nas batalhas }\end{array}$ & BR 1876b:4 \\
\hline Igassáuas & $\begin{array}{l}\text { Duas espécies: para guardar água e para } \\
\text { depositar as bebidas inebriantes... e as que } \\
\text { outrora serviam como urnas funerárias, } \\
\text { cujas formas são diversas }\end{array}$ & BR 1876b:19 \\
\hline Inuriucháua apecú & $\begin{array}{l}\text { Assento de chefe. Decoração de bonito efeito, } \\
\text { feito por compressão de tecido de peneiras ou } \\
\text { tipiti. Era pouco usada }\end{array}$ & BR 1876b:17 \\
\hline Itapuquity & $\begin{array}{l}\text { Ita }=\text { pedra, puquity }=\text { esfregar. Pequeno seixo } \\
\text { usado para lustrar (polir) a superfície da vasilha } \\
\text { antes da queima }\end{array}$ & BR 1876b:15 \\
\hline Iucaçaua & Pote de ossos (LG) & BR 1892b:74 \\
\hline Iucaháu & Pote de ossos $(\mathrm{Av})$ & BR 1892b:74 \\
\hline Iukaçauas & $\begin{array}{l}\text { urnas ossuárias, as que encerravam ossadas } \\
\text { completas, sem terem sido levadas ao fogo } \\
\text { e que em baixo relevo representam diferentes } \\
\text { para de uma figura humana com indicação } \\
\text { de sexo }\end{array}$ & BR 1892a:13 \\
\hline Juba & Amarelo $(\mathrm{Nh})$ & BR 1892b:44 \\
\hline Jutahy icica & $\begin{array}{l}\text { Resina de jataí (Hymenea courbari) } \\
\text { usada para vidrar a parede interna }\end{array}$ & BR 1876b:18 \\
\hline Kamoti & Pote & BR 1876b:10 \\
\hline Kamucí & $\begin{array}{l}\text { urnas cinerárias, as que continham o pó } \\
\text { e as cinzas das ossadas. Estas urnas têm } \\
\text { a forma de um pote e raras vezes têm indícios } \\
\text { de partes do corpo humano }\end{array}$ & BR 1892a:14 \\
\hline
\end{tabular}




\begin{tabular}{|c|c|c|}
\hline Kamucí uaçu & $\begin{array}{l}\text { O grande pote no qual dissolviam a tinta e nela } \\
\text { misturavam o pó e as cinzas dos ossos }\end{array}$ & BR 1892a:14 \\
\hline Kamuty & Para [conter] o cachiry e o tarupá & BR 1876b:4 \\
\hline Kanguera reru & $\begin{array}{l}\text { urnas ossuárias, as que encerravam ossadas } \\
\text { queimadas e partidas, algumas semelhantes } \\
\text { às primeiras [ikuaçauas] e outras sem indicar } \\
\text { forma alguma humana e destituída de relevos }\end{array}$ & BR 1892a:14 \\
\hline Kanguera-çaua & $\begin{array}{l}\text { Taças cinerárias em que se derramava a tinta } \\
\text { incinerada. São ornadas com emblemas antro- } \\
\text { pomorfos e zoomorfos }\end{array}$ & BR 1892a:14 \\
\hline Miasáua & $\begin{array}{l}\text { Imitação de trançado de palha, com cruza- } \\
\text { mento das linhas obliquamente formando } \\
\text { quadrados }\end{array}$ & BR 1876b:16 \\
\hline Moroting & Branco (Av) & BR 1892b:49 \\
\hline Morotinga & Branco (LG) & BR 1892b:49 \\
\hline Motauá & Pintar de amarelo (Av) & BR 1892b:78 \\
\hline Mumurutinga & Pintar de branco (Nh) & BR 1892b:78 \\
\hline Mupiranga & Pintar de encarnado (Nh) & BR 1892b:78 \\
\hline Mupixuna & Pintar de preto $(\mathrm{Nh})$ & BR 1892b:78 \\
\hline Murutinga & Branco (Nh) & BR 1892b:49 \\
\hline Mutauá & Pintar de amarelo (Nh) & BR 1892b:78 \\
\hline Nhaé & Alguidar (LG) & BR 1892b:43 \\
\hline Nhaé & Alguidar (Av) & BR 1892b:43 \\
\hline Nhaen pepó & Panela (LG) & BR 1892b:71 \\
\hline Nhaen pepó & Panela (Av) & BR 1892b:71 \\
\hline Nheê & Alguidar (Nh) & BR 1892b:43 \\
\hline Pichun & Negro (Av) & BR 1892b:69 \\
\hline Pichuna & Negro (LG) & BR 1892b:69 \\
\hline $\begin{array}{l}\text { Pinima mumurut- } \\
\text { inga irumo }\end{array}$ & Pintar de branco (LG) & BR 1892b:78 \\
\hline $\begin{array}{l}\text { Pinima mupixuna } \\
\text { irumo }\end{array}$ & Pintar de preto (LG) & BR 1892b:78 \\
\hline $\begin{array}{l}\text { Pinima piranga } \\
\text { irumo }\end{array}$ & Pintar de encarnado (LG) & BR 1892b:78 \\
\hline Pinima tauá irumo & Pintar de amarelo (LG) & BR 1892b:78 \\
\hline Pirang & Encarnado $(\mathrm{Av})$ & BR 1892b:56 \\
\hline Pirang & Vermelho (Av) & BR 1892b:83 \\
\hline Piranga & Encarnado (Nh) & BR 1892b:56 \\
\hline Piranga & Encarnado (LG) & BR 1892b:56 \\
\hline
\end{tabular}




\begin{tabular}{|c|c|c|}
\hline Piranga & Vermelho (Nh) & BR 1892b:83 \\
\hline Piranga & Vermelho (LG) & BR 1892b:83 \\
\hline Pixuna & Negro (Nh) & BR 1892b:69 \\
\hline Reru & Vaso, vasilha (LG) & BR 1892b:82 \\
\hline Saracura pepóra & $\begin{array}{l}\text { Pegada de saracura. Decoração de bonito } \\
\text { efeito, pouco usada }\end{array}$ & BR 1876b:17 \\
\hline Tabatinga & Argila "branca" preferida para fazer vasilhas & BR 1876b:11 \\
\hline Tamuatá pirêra & $\begin{array}{l}\text { Decoração pontilhada incisa feita com espinho } \\
\text { de tucumã }\end{array}$ & BR 1876b:16 \\
\hline Tamuatá pirêra & $\begin{array}{l}\text { Decoração formando como que escamas, em } \\
\text { ângulos opostos concêntricos }\end{array}$ & BR 1875b:90 \\
\hline Tapururapé & $\begin{array}{l}\text { Decoração: Tapurú = bicho, apé = caminho. } \\
\text { Linha em zig-zag }\end{array}$ & BR 1876b:17 \\
\hline Tapurú rapé & Decoração: Caminho de bicho & BR 1875b:90 \\
\hline Tauá & Barro amarelo $(\mathrm{Nh})$ & BR 1892b:47 \\
\hline Tauá & Barro amarelo (LG) & BR 1892b:47 \\
\hline Tauá & Barro amarelo (Av) & BR 1892b:47 \\
\hline Tauá & Amarelo (Nh) & BR 1892b:44 \\
\hline Tauá & Amarelo (LG) & BR 1892b:44 \\
\hline Tauá & Amarelo $(\mathrm{Av})$ & BR 1892b:44 \\
\hline Taua juba & $\begin{array}{l}\text { Argila escura misturada com vegetais e partícu- } \\
\text { las de aryuauá, para formar pigmento preto }\end{array}$ & BR 1876b:17 \\
\hline Tauá juba & Argila não empregada na confecção de vasilhas & BR 1876b:11 \\
\hline Tauá piranga & Argila não empregada na confecção de vasilhas & BR 1876b:11 \\
\hline Tauatinga & Gesso, usado como pigmento branco & BR 1876b:17 \\
\hline Ting & Branco (Av) & BR 1892b:49 \\
\hline Tinga & Branco $(\mathrm{Nh})$ & BR 1892b:49 \\
\hline Tinga & Branco (LG) & BR 1892b:49 \\
\hline Tykuçaua & $\begin{array}{l}\text { Espécie de bydria dos gregos, que servia para } \\
\text { derramar a tinta nas kangueraçauas }\end{array}$ & BR 1892a:14 \\
\hline Yaraki-çaua & $\begin{array}{l}\text { Taça das libações, com forma de panelas mais } \\
\text { ou menos ornadas, algumas com emblemas } \\
\text { zoomorfos, em relevo }\end{array}$ & BR 1892a:14 \\
\hline Ygahau & Pote de água $(\mathrm{Av})$ & BR 1892b:74 \\
\hline Yub & Amarelo (Av) & BR 1892b:44 \\
\hline Yuba & Amarelo (LG) & BR 1892b:44 \\
\hline
\end{tabular}




\section{NOTAS}

${ }^{1}$ Estamos preparando uma biografia (Noelli e Ferreira s/d) de todas as pesquisas, idéias e controvérsias sobre Barbosa Rodrigues como arqueólogo. Ao contrário do que apresentaremos neste artigo, aspectos específicos de uma parte dos métodos, na biografia descreveremos mais os diálogos internacionais travados por Barbosa Rodrigues.

${ }^{2}$ Foi uma das formas como Barbosa Rodrigues grafou o termo Guarani.

${ }^{3}$ Exemplo de instituições que abrigavam pesquisa Arqueológica no século XIX, algumas mantiveram intercâmbio com o IHGB: American Antiquarian Society (1812), Society of Antiquaries of Newcastle upon Tyne (1813), Société des Antiquaires de Normandie (1824), Kongelige Nordiske Oldskriftselskab (Sociedade Real dos Antiquários do Norte) (1825), Deutsche Gesellschaft zur Erforschung vaterländischer Sprache und Alterthümer (German Society for Research on the German Language and Antiquities) (1827), Keninklik Frysk Genoatskip foar Skiednis en Kultuer (Frisian Society for History and Culture) (1827), Société de Statistique, d'Histoire et d'Archéologie de Marseille et de Provence (1827), Kongelige Nordiske Oldskriftselskab (Sociedade Real dos Antiquários do Norte, 1825), Société Archéologique du Midi de la France (1831), Antiquarische Gesellschaft in Zürich (Sociedade dos Antiquários de Zürich, 1832), Société Française d'Archéologie (1834), Société d'Histoire et d'Archéologie de Genève (1838), Sociedade dos Antiquários da França, Société Ethnologique de Paris (1839), American Ethnological Society (1842), Ethnological Society of London (1843), Archaeological Institute of Great Britain and Ireland (1844), Smithsonian Institution (1846), Императорское Русское Археологическое Общество (Sociedade Arqueológica Imperial Russa, 1846), So- ciété d'Anthropologie de Paris (1859), a London Anthropological Society (1863), a Berliner Gesellschaft für Anthropologie, Ethnologie und Urgeschichte (1869), Anthropological Institute of Great Britain and Ireland (1871) e o Bureau of Ethno$\operatorname{logy}(1879)$ da Smithsonian Institution.

\section{REFERÊNCIAS}

Adams, W. \& E.W. Adams. 1991. Archaeological typology and practical reality. A dialectical approach to artifact classification and sorting. Cambridge: Cambridge University Press.

Balée, W. 1994. Footprints of the Forest. Ka'apor Ethnobotany - the Historical Ecology of plant utilization by an Amazonian people. New York: Columbia University Press.

2000. Antiquity of traditional ethnobiological knowledge in Amazonia: The Tupí-Guaraní family and time. Ethnohistory 47(2):399-422.

Barbosa, J. da C. 1839. Lembrança: Do que devem procurar nas províncias os sócios do Instituto Histórico Brasileiro, para remeterem à sociedade central do Rio de Janeiro. RIHGB (1): 141-143.

Barbosa Rodrigues, J. 1875a. Exploração dos rios Urubú e Jatapú. Rio de Janeiro: Typographia Nacional.

. 1875b. Exploração do rio Yamundá. Rio de Janeiro: Typographia Nacional.

. 1875c. Exploração e estudos do Vale do Amazonas: Rio Tapajós. Rio de Janeiro: Typographia Nacional.

1875d. Ídolo amazônico achado no rio Amazonas. Rio de Janeiro: Brown \& Evaristo.

. 1876a. Antiguidades do Amazonas. Armas e instrumentos de pedra. Ensaios de Sciencia por diversos amadores 1:91-125.

. 1876b. Antiguidades do Amazonas. Arte cerâmica. Ensaios de Sciencia por diversos amadores 2:3-23.

1880a. Antiguidades do Amazonas. 
Aterros sepulcrais. Ensaios de Sciencia por diversos amadores 3:3-53.

1880b. Observações sobre as duas urnas descritas e figurada pelo Sr. Ferreira Penna em seu artigo - Apontamentos sobre os ceramios do Pará inserto na revista Arquivos do Museu Nacional. Ensaios de Sciencia por diversos amadores 3: 57-74.

1881. Lendas, crenças e superstições. Revista Brazileira 10: 24-47.

1885. Rio Janapery. A pacificação dos Crichanás. Rio de Janeiro: Imprensa Nacional.

1889. O muyrakytã. Estudo da origem, análise da civilização do Amazonas nos tempos prehistóricos. Manaus: Typographia do Amazonas.

1890. Poranduba Amazonense: on kochymaura porandub. Rio de Janeiro: G. Leuzinger e Filhos.

. 1891. Prólogo. Vellosia. Contribuições do Museu Botânico do Amazonas 1: V-XX.

1892a. Antiguidades do Amazonas. A necrópole de Mirakangüéra. Vellosia. Contribuições do Museu Botânico do Amazonas (Arqueologia e Paleontologia, 1885-1888) 2: $1-40$.

1892b. Vocabulário indígena comparado para mostrar a adulteração da língua (complemento do Poranduba Amazonense). Rio de Janeiro: Biblioteca Nacional.

1899. O muyrakytã e os ídolos simbólicos. Estudo da origem asiática da civilização do Amazonas nos tempos pré-históricos. v. 1.Rio de Janeiro: Biblioteca Nacional.

1899. O muyrakytã e os ídolos simbólicos. Estudo da origem asiática da civilização do Amazonas nos tempos pré-históricos. v. 2.Rio de Janeiro: Biblioteca Nacional.

1905. Mbaé kaá tapyiyeta enoyndua ou a botânica e a nomenclatura indígena. Rio de Janeiro: Imprensa Nacional.

Barros, M. C. D, M. 1990. Uma visão romântica da língua Tupi. Amerindia 15:85-94.

Boas, F. 1902. Some problems in North
American Archaeology. American Journal of Archaeology 6(1):1- 6.

Couto de Magalhães, J. V. de. 1873. Ensaio de Antropologia. RIHGB (36): 359-516.

Couto de Magalhães, J. V. de. 1935 [1876]. O Selvagem. 2 ed. Rio de Janeirro: Companhia Editora Nacional.

Daniel, G. 1950. A Hundred Years of Archaeology. London: Duckworth.

Edelweiss, F. G. 1969. Estudos Tupis e TupiGuaranis. Confrontos e revisões. $2^{\mathrm{a}} \mathrm{ed}$. Rio de Janeiro: Livraria Brasiliana.

Ferreira, L. M. 1999. Vestígios de Civilização: O Instituto Histórico e Geográfico Brasileiro e a Construção da Arqueologia Imperial (1838-1870). Revista de História Regional 4: 9-36.

2002. Vestígios de Civilização: A Arqueologia no Brasil Imperial (1838-1877). Dissertação de Mestrado. Campinas: Universidade Estadual de Campinas.

2006. Ciência Nômade: O IHGB e as viagens científicas no Brasil Imperial. História, Ciências, Saúde - Manguinhos 13:271-292.

2007. Território Primitivo: A Institucionalização da Arqueologia no Brasil (1870-1917). Tese de Doutorado. Campinas: Universidade Estadual de Campinas.

Goodrum, M. 2002. The Meaning of Ceurania: Archaeology, natural history and the interpretation of stone artefacts in eighteenth century. The British Journal for the History of Science 35(3): 255-269.

Groenen, M. 1994. Por une Histoire de la Prébistoire. Grenoble: Éditions Jérome Millon.

Harris, M. The rise of Anthropological theory. New York: Crowell, 1968.

Hartt, C. F. 1872. Notes on the Lingoa Geral, or modern Tupi of Amazonas. Transactions of the American Philological Association (1869-1896) 3:58-76.

Hartt, C. F. 1937. Notas sobre a Língua Geral, ou o Tupi moderno do Amazonas. 
Anais da Biblioteca Nacional 51:303-390.

Ihering, H. 1911. João Barbosa Rodrigues. Revista do Musen Paulista 8:23-37.

Lubbock, J. 1865. The prehistoric times. Edinburgh: Willians and Norgate.

Martius, K. P. von. 1840. Carta de von Martius, lida na $44^{a}$ Sessão em $1^{\circ}$ de agosto de 1840. RIHGB 2: 399-401.

1844. Como se deve Escrever a História do Brasil. RIHGB 6: 389-411.

1854. Systema de materia medica vegetal brasileira. Rio de Janeiro: Laemmert.

1867. Beiträge zur Ethnographie und Sprachenkunde Amerika's zumal Brasiliens. Leipzig : F. Fleischer. v. 1

1867. Wörtersammlung Brasilianischer Sprachen. Glossaria Linguarum Brasiliensium: Glossários de Diversas Linguas e Dialetos que Falam os Índios no Império do Brasil. Leipzig: F. Fleischer. v. 2.

1905 [1838]. Etnografia Americana:

O Passado e o Futuro do Homem Americano. RIHGSP 9: 534-562.

1939 [1844]. Natureza, doencas, medicina e remédios dos indios brasileiros. São Paulo: Nacional.

Mayr, E. 1971. Methods and strategies in taxonomic research. Systematic Zoology 20(4): 426-433.

Moore, D., S. Facundes \& N. Pires. 1993. Nheengatu (Língua Geral Amazônica), its history, and the effects of language contact. Survey of California and other Indian Languages 8: 93-118. Berkeley: University of California.

Mori, S \& Ferreira, F. 1987. A distinguished Brazilian botanist, João Barbosa Rodrigues (1842-1909). Brittonia 39(1):73-85.

Noelli, F. S. 2008. José Proenza Brochado: vida acadêmica e a arqueologia Tupi, in Tradição Tupi-Guarani. Editado por A. Prous e T.A. pp. 17-47. Lima. Belo Horizonte: Sigma/IPHAN.

Noelli, F. S. \& L. M. Ferreira. 2007. A persistência da teoria da degeneração e do colonialismo nos fundamentos da Arqueologia Brasileira. História, Ciências, Saúde - Manguinhos 14(4): 1239-1264.

s.d. Biografia arqueológica de João Barbosa Rodrigues (no prelo).

Nogueira, B. C. A. 1876a. Apontamentos sobre o Abañeenga, também chamado Guarani ou Tupi Língua Geral dos Brasis. Ensaios de Sciencia por diversos amadores 1:1-77. 1876b. Língua Geral dos Brasis. O Colóquio de Léry. Ensaios de Sciencia por diversos amadores 2:1-132.

Porto, F. C. 1892. Histórico do Museu Botânico do Amazonas. Vellosia. Contribuiçoes do Museu Botânico do Amazonas 2:61-80.

Rodrigues, A. D. 1958. Classification of Tupi-Guarani. International Journal of American Linguistics 24:231-234.

Romero, S. 1888. Ethnographia Brazileira. Estudos críticos sobre Couto de Magalhães, Barbosa Rodrigues, Theopbilo Braga e Ladislao Netto. Rio de Janeiro: Livraria Clássica de Alves \& Cia.

Roosevelt, A. C. 1991. Moundbuilders of the Amazon. New York: Academic Press.

Sá, M. R. 2001. O botânico e o mecenas: João Barbosa Rodrigues e a ciência no Brasil na segunda metade do século XIX. História, Ciências e Saúde - Manguinhos 8:899-924.

Shapin, S. 1974. Property, Patronage, and the Politics of Science: The Founding of the Royal Society of Edinburgh. The British Journal for the History of Science 7(1): 1-41.

Stiebing, W. H. Jr. 1993. Uncovering the Past: A History of Archaeology. Oxford: Oxford U. P.

Trigger, B. G. A History of Archaeological Thought. 2nd ed. Cambridge: Cambridge U. P., 2006.

Willey, G. R. \& J.A.SABLOFF. 1980. A History of American Archaeology. $2^{\mathrm{a}}$ ed. San Francisco: Freeman. 